\title{
As modalidades de tradução na legendagem de fãs ${ }^{1}$
}

\author{
Ana Katarinna Pessoa do Nascimento*
}

\section{Introdução}

Chaume (2004) define "legendagem" como uma prática tradutória que consiste em apresentar o texto escrito, geralmente na parte inferior da tela, de modo que as inserções coincidam com as falas dos personagens. Cintas e Remael (2007) acrescentam ainda que a legendagem deve traduzir também elementos discursivos que apareçam nas imagens e demais informações linguísticas presentes na trilha sonora.

Para Gottlieb (1995), a legendagem é uma tradução aberta pois é apresentada simultaneamente com o original, o que a deixa vulnerável a críticas; além disso, é também fragmentada, já que não apresenta as características prosódicas naturais do discurso, meramente buscando representá-las por meio de sinais gráficos. Apesar desses fatores, é um dos tipos de tradução audiovisual (TAV) mais utilizados no mundo (Chaume, 2004).

Com o advento de sites e programas em que usuários de todo o mundo disponibilizam online filmes e seriados, surgiu a necessidade de uma forma rápida e eficaz de tradução desses produtos audiovisuais. A propagação de softwares gratuitos de legendagem fez com que essa forma de tradução fosse a escolhida, e a legendagem de fãs, a partir de meados dos anos 2000, tornou-se prática comum entre internautas que usam a web para fazer downloads de filmes e séries de TV em língua estrangeira.

Tendo em vista a popularização dessa prática, este trabalho busca analisar as modalidades de tradução propostas por Aubert $(1998 ; 2006)$ nas

\footnotetext{
${ }^{1}$ Comunicação oral apresentada no VIII Seminário de Tradução da UFBA em 2014.

* Doutoranda em Estudos da Tradução pela Universidade de São Paulo.
} 
estratégias de legendistas não profissionais. Foi escolhido como corpus para a pesquisa um episódio da série americana de televisão chamada Game of thrones, apontada como o seriado com maior número de downloads no ano de 2013.

A fim de facilitar a visualização das ocorrências das modalidades ao longo dos dois textos, a legendagem feita por fãs, em língua portuguesa, e a legendagem profissional, em língua inglesa, foram alinhadas com o utilitário Viewer \& Aligner do programa de análise lexical WordsSmith Tools. O alinhamento considerou a maneira como cada legenda foi reproduzida no texto meta. Concomitantemente à identificação das modalidades no corpus, cada uma das modalidades de tradução encontrada foi etiquetada. Posteriormente, esses dados foram inseridos na ferramenta Concord para, então, proceder-se à quantificação das modalidades de tradução e sua identificação em contexto.

Com essa metodologia, a presente pesquisa busca descobrir quais as modalidades de tradução mais utilizadas pelos legendistas amadores e se essas estão, de alguma forma, associadas às estratégias de redução textual próprias do gênero legendagem, que devem levar em conta o limitado tempo disponível em tela para a leitura dos textos e a linguagem multimodal de um produto audiovisual.

\section{Fundamentação teórica}

\subsection{Legendagem}

De acordo com Cintas \& Remael (2007), todos os programas legendados possuem três componentes: a trilha sonora (fala, música e ruídos), a imagem e a legenda. Para que o produto audiovisual seja bem compreendido pelo espectador, esses componentes devem estar em sincronismo (Araújo, 2004). Por isso, a legendagem possui algumas características técnicas que devem ser observadas.

A marcação determina os tempos de entrada e saída da legenda na tela. A principal regra é que as legendas devem manter sincronismo com as falas, ou seja, sempre que possível, a legenda deve aparecer no momento em que se inicia a fala e desaparecer quando a pessoa para de falar (Cintas \& Remael, 2007). 
A fim de se obter uma legenda de qualidade é preciso respeitar o tempo mínimo de leitura. Esse tempo mínimo ideal de exposição da legenda na tela é comumente acordado em um segundo para até dezesseis caracteres (Ibid.). Além disso, é preciso atentar também para o tempo máximo de permanência da legenda na tela, a fim de evitar a releitura desnecessária ( $\mathrm{D}^{\prime} \mathrm{Y}$ dewalle et al., 1987; Ivarsson \& Carol, 1998). No Brasil, o tempo máximo de permanência é de quatro segundos (Araújo, 2004). Isso significa que nas legendas brasileiras as falas com maior duração têm permanência de até quatro segundos na tela, com o número máximo de 58 caracteres para esse tempo. Para adequar o que é dito no tempo disponível da legenda, existem três velocidades: a mais lenta é de 145 palavras por minuto (ppm), a de velocidade média, 160 ppm, e a mais rápida, de 180 ppm. A velocidade mais utilizada no Brasil é a de 145 ppm, a mais baixa, na qual é possível inserir até 16 caracteres em um segundo, incluindo espaços entre palavras e pontuação. No exemplo a seguir, tem-se 1 segundo e 100 milésimos para 15 caracteres na legenda do filme Vaqueiros, de Éder Bicudo.

\begin{tabular}{|c|c|}
\hline Tempo & Legenda \\
\hline $00: 59: 57,153 \rightarrow 00: 59: 58,263$ & O neto do vovô. \\
\hline
\end{tabular}

Quadro 1: Legenda de 1 segundo de duração

Com o intuito de respeitar esse padrão, recomenda-se reduzir os textos das legendas em relação às falas. Segundo Cintas \& Remael (2007), existem dois tipos de redução textual: a total e a parcial. A primeira ocorre quando há omissão ou apagamento de itens lexicais; a segunda, quando há condensação. Os autores afirmam ainda que essas estratégias só devem ser usadas quando estritamente necessário, pois se houver tempo de inserir as falas por completo isso deve ser feito.

Na seção a seguir serão apresentadas algumas características próprias da legendagem de fãs. 


\subsubsection{Legendagem feita por fãs}

Esse tipo de legenda começou a se popularizar na segunda metade da década de 2000 na medida em que se tornou possível fazer o download de seriados estrangeiros pela internet. Muitas pessoas não conseguiam acompanhar a trama por não compreender a língua em que o programa era falado. Isso levou alguns grupos de amigos que gostavam das séries e/ou filmes, e compreendiam a língua estrangeira, a produzirem eles mesmos as legendas e disponibilizá-las para outros fãs. Essa prática começou a se difundir, e hoje existem sites especializados para quem produz ou busca essas legendas.

Atualmente, as equipes de legendagem não são mais compostas exclusivamente por amigos. A atividade tornou-se tão popular que pessoas de localidades diferentes, que nunca se encontraram, fazem parte de uma mesma equipe de legendistas. Bastante organizadas, as equipes dividem entre si quais séries e filmes serão legendados; dessa forma é provável que uma mesma equipe faça as legendas de várias - ou todas - as temporadas de uma série de TV.

O site da equipe Insubs descreve o processo de confecção de legendas:

Para seguirmos todos esses padrões, precisamos de tradutores e revisores em cada equipe. Os tradutores, como o nome diz, traduzem um pedacinho de cada série. Cabe ao revisor juntar tudo, ver se a tradução está bem feita, olhar a sincronia, padronizar os termos usados na série, corrigir o português... Ufa! É muita coisa. Enquanto um tradutor faz a parte dele em umas duas horas (dependendo da série e do tamanho da parte dele), o revisor pode levar até dois ou três dias pra dar conta de tudo e deixar a legenda perfeitinha e pronta para ser postada. (Equipe Insubs, 2014)

Os legendistas amadores não são remunerados para desempenhar a atividade tradutória e muitos não são versados nos estudos da tradução. No entanto, o site do grupo Insubs apresenta algumas questões técnicas que devem ser seguidas por todos os membros:

Exposição mínima da legenda na tela de 1.3 segundos; Exposição máxima da legenda na tela de 6 segundos; Máximo de 23 caracteres por segundo (permite ler a legenda inteira, sem que ela fique na tela menos tempo que o necessário); Máximo de 32 caracteres por linha (muitos players não leem frases maiores do que essa); Postar a legenda em no máximo 7 dias depois que o episódio foi ao ar nos EUA (no caso de séries. Para filmes, é diferente). (Equipe Insubs, 2014) 
Para ter acesso às legendas de fãs, o usuário precisa baixá-las da internet. Existem inúmeros sites que disponibilizam as legendas. Em geral, os arquivos estão em formato .srt e podem ser lidos por diversos softwares de vídeo.

Na seção seguinte será abordado o tema das modalidades de tradução propostas por Aubert (1998; 2006).

\subsection{Modalidades de tradução}

Baseado nos procedimentos técnicos da tradução de Vinay \& Darbelnet, Aubert (1998, p. 102) propôs um "modelo descritivo mediante o qual o grau de diferenciação linguística entre o texto original e o texto traduzido pode ser medido e quantificado". Um dos objetivos do autor era a possibilidade de analisar estatisticamente os textos traduzidos, área que não era comumente estudada por esse viés.

Em 2006 Aubert fez uma revisão das modalidades de tradução propostas no artigo de 1998. Isso se deu, segundo o autor, a partir da necessidade de se levar em consideração não apenas a língua, mas também como cada modalidade afeta os textos.

É importante notar que essa abordagem pressupõe uma verificação detalhada dos textos fonte e alvo, pois a análise da ocorrência das modalidades considera cada palavra em seu contexto fonte, e como essa foi "resgatada" no texto meta analisado.

A primeira modalidade descrita é a omissão, que consiste em informação contida no texto fonte que não pode ser encontrada no texto meta. A modalidade do espelhamento ocorre quando um segmento do texto fonte aparece no texto meta com pequena ou nenhuma modificação. Divide-se em dois tipos: o empréstimo, que é a repetição de segmentos do texto fonte (TF) no texto meta (TM) (com ou sem marcadores de empréstimo com as aspas); e o decalque, no qual o segmento do TF sofre adaptações para se adequar às convenções da língua meta (Aubert, 2006).

Ainda segundo o mesmo autor (Ibid.), outra modalidade de tradução é a literalidade, na qual as soluções tradutórias são diretas, utilizando-se de sinônimos interlinguísticos e interculturais. Existem quatro tipos de literalidade: a transcrição, que inclui segmentos de texto que pertençam a ambas as 
línguas do processo tradutório, ou ainda, que não pertençam a nenhuma delas, como por exemplo um texto escrito em inglês e traduzido para o português, com algumas passagens em italiano que se repetem no TF e TM; a tradução palavra por palavra, na qual é preciso preencher os seguintes requisitos: (1) o mesmo número de palavras, (2) na mesma ordem sintática, (3) empregando as mesmas categorias gramaticais, (4) contendo as opções lexicais que, no contexto específico, podem ser tidas como sendo sinônimos interlinguais; a transposição, quando um ou mais critérios da tradução palavra por palavra não ocorre; e por fim a explicitação, em que o tradutor busca manter (ou até mesmo explicar) o sentido do texto, por meio de diversos recursos, tais como notas de rodapé, aposto explicativo e glossário.

Existe ainda a modalidade da equivalência, em que a presença do tradutor torna-se mais evidente, e que pode ser de três tipos: a implicitação, em que informações explícitas no TF aparecem implícitas no TM; a explicitação, que é o oposto; e a modulação, que consiste em mudança na estrutura semântica, mas possui o mesmo efeito geral de sentido (Ibid.). Através do modo de dizer próprio da cultura para qual o texto está sendo traduzido, essa é a modalidade que melhor revela a cultura linguística do TM. De acordo com o exemplo a seguir, tem-se a expressão em inglês sit as judge, que em português, o tradutor optou por "ser o juiz".

\begin{tabular}{|l|l|}
\hline Inglês & will sit as judge in my stead. \\
\hline Português & será o juiz no meu lugar. \\
\hline
\end{tabular}

Quadro 2: Exemplo de Modulação

Na modalidade equivalência, para Aubert (2006), entende-se a mesma coisa por outros caminhos. O mesmo ocorre na adaptação, na qual há o abandono da busca de equivalência plena, e que para o autor pode ser tida como um embate entre as duas realidades extralinguísticas que se confrontam no ato tradutório.

Além dos processos citados acima, há também a tradução intersemiótica, que no texto literário ocorre usualmente nas ilustrações e nas capas. E, 
por fim, o erro, no qual há troca injustificada de sentido, ultrapassando as fronteiras da adaptação (Ibid.).

Aubert (2006) destaca que essa revisão abandonou a classificação linear das modalidades e possibilitou o seu agrupamento em grandes classes: espelhamento, literalidade e equivalência. Esse agrupamento possibilitou a separação dos automatismos, que ocorrem por efeito da própria estrutura das línguas e das intencionalidades manifestas do tradutor, pensadas durante sua prática tradutória em concreto. Ou seja, possibilitou a percepção não apenas das escolhas pontuais do tradutor em sua prática, mas também conjecturar a motivação delas.

\section{Metodologia}

\section{1. $\mathrm{O}$ corpus}

O corpus da presente pesquisa é paralelo bilíngue, composto por uma legendagem em inglês para surdos e ensurdecidos e uma legendagem em português brasileiro para ouvintes.

$O$ arquivo de legenda em inglês possui 775 inserções, enquanto o arquivo em português apresenta apenas 645. A grande diferença se dá porque a legenda em inglês tem como público alvo surdos e ensurdecidos e por isso acrescenta legendas de efeitos sonoros. Para estudo do corpus, as legendas de efeitos sonoros em inglês, bem como os números de entrada e saída das legendas na tela, foram retiradas.

A série cujo episódio compõe o corpus chama-se Game of thrones, é baseada em uma série de livros de nome "As crônicas de gelo e fogo" e exibida no Brasil pelo canal pago HBO. Bastante popular entre os espectadores, foi a série com maior número de downloads efetuados em $2013^{2}$. O episódio selecionado para a pesquisa chama-se "The laws of gods and men", de número seis da quarta temporada da série; possui 52 minutos e foi escolhido por ter sido o último a ser exibido (em 11 de maio de 2014) ao se iniciar a presente pesquisa.

\footnotetext{
${ }^{2}$ Segundo o site TorrentFreak, que contabilizou os números de séries baixadas pelo BitTorrent, uma das formas mais populares de download no mundo.
} 


\subsection{Procedimentos de pesquisa}

O corpus utilizado é composto por dois arquivos de legenda baixados da internet no formato .srt, extensão mais utilizada por legendistas amadores. Esses arquivos foram modificados para extensão .txt, e dessa forma puderam ser lidos pelo programa WordSmith Tools, mais precisamente pelo utilitário Viewer and Aligner (Figura 1). Esse utilitário possibilita o alinhamento de duas ou mais versões de um mesmo texto, apresentando alternadamente frases ou parágrafos de cada texto. Isso permite que cada legenda seja observada paralelamente no texto fonte e no texto meta.

Diferentemente do que se tem em Aubert (1998; 2006), as unidades de tradução utilizadas no presente trabalho não são necessariamente as palavras, mas seguem a proposta de Alves (2013, p. 38): "unidade de tradução é um segmento do texto de partida, independente de tamanho e forma específicos, para o qual, em um dado momento, se dirige o foco de atenção do tradutor". Esse conceito de unidade de tradução foi levado em conta graças ao gênero em questão, no qual o espectador deve ler a legenda como um todo e essa deve ser compreendida como uma unidade.

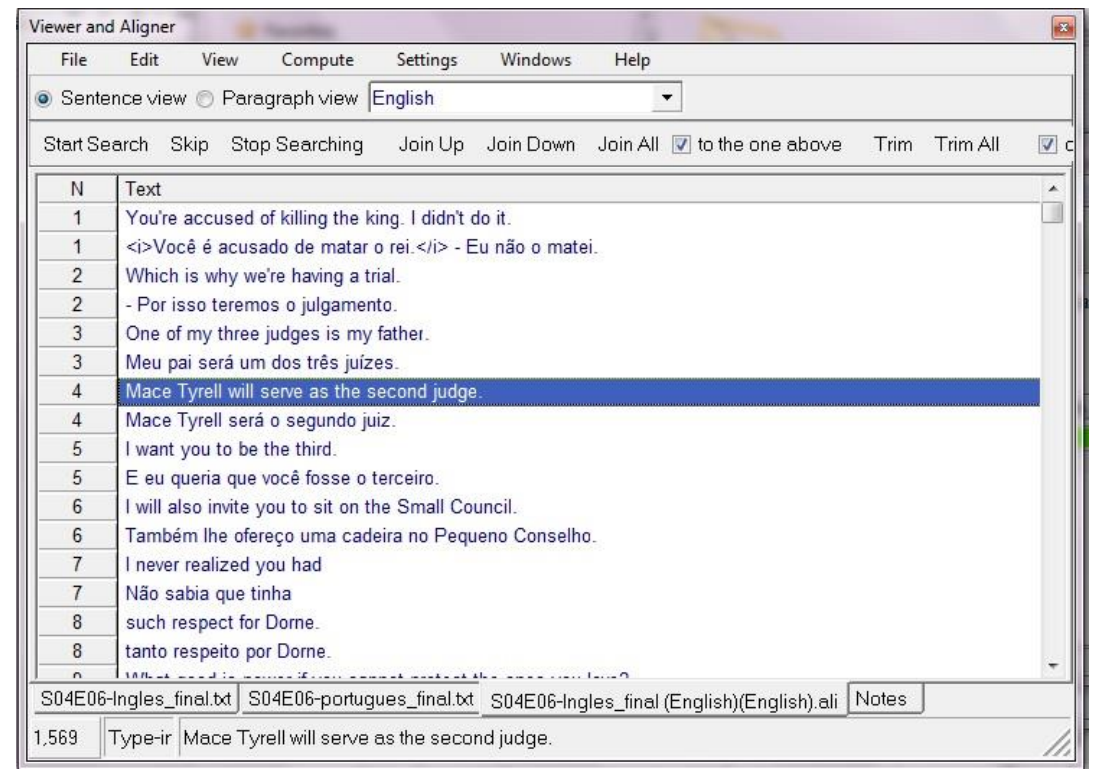

Figura 1: Alinhamento

Concomitantemente à observação do corpus paralelo no Viewer \& Aligner foi feita a etiquetagem do corpus com as modalidades de tradução, 
na medida em que essas eram encontradas nas legendas em português. Isso facilitou o processo de quantificação das etiquetas, pois a ferramenta Concord permite ver o número de vezes que cada uma aparece quando se faz a busca pelo nome. Dessa forma foi possível quantificar quais as modalidades de tradução mais utilizadas pelos legendistas amadores, além de verificar cada ocorrência em contexto (Figura 2). Assim, foi possível analisar se estão associadas às estratégias de redução textual próprias do gênero legendagem, que é o principal objetivo desta pesquisa.

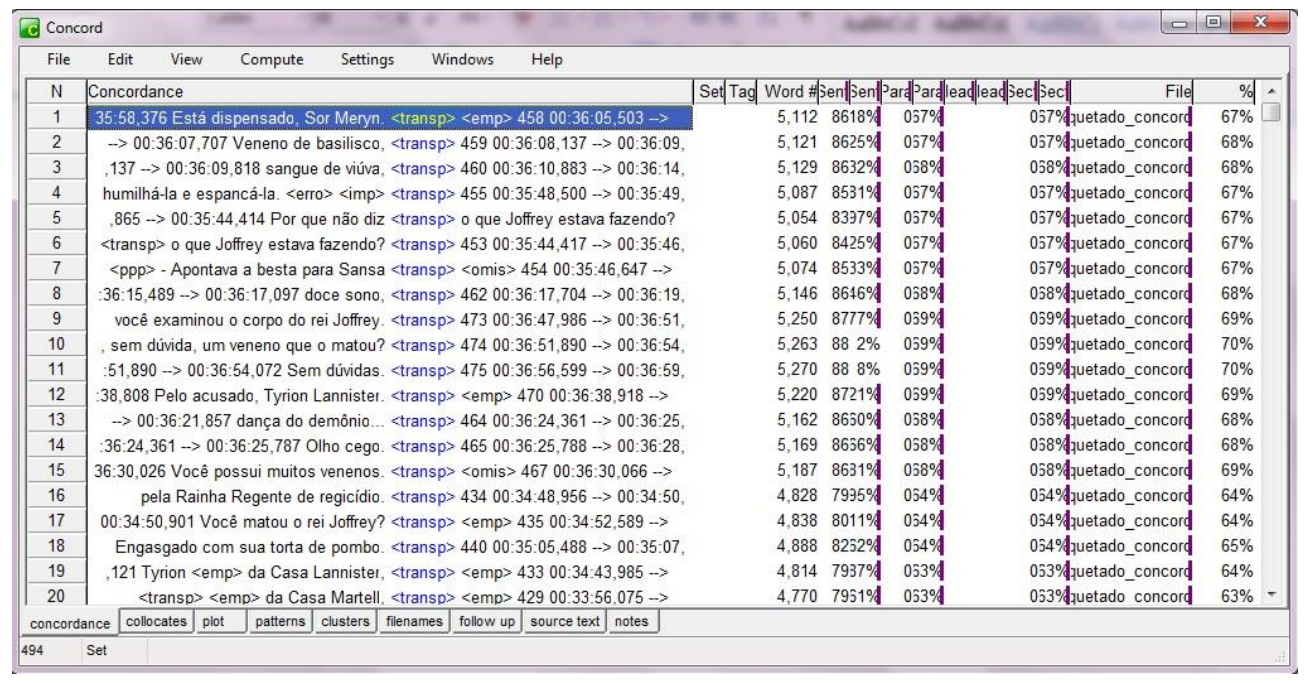

Figura 2: Concordância para a etiqueta Transposição

Como o corpus analisado é um texto audiovisual, as imagens e efeitos sonoros não verbais do episódio também podem ter grande importância no processo tradutório e, conjuntamente com as falas, devem ser levados em conta. Nesse caso, o arquivo de vídeo com o episódio foi consultado sempre que necessário. 


\section{Análise dos dados}

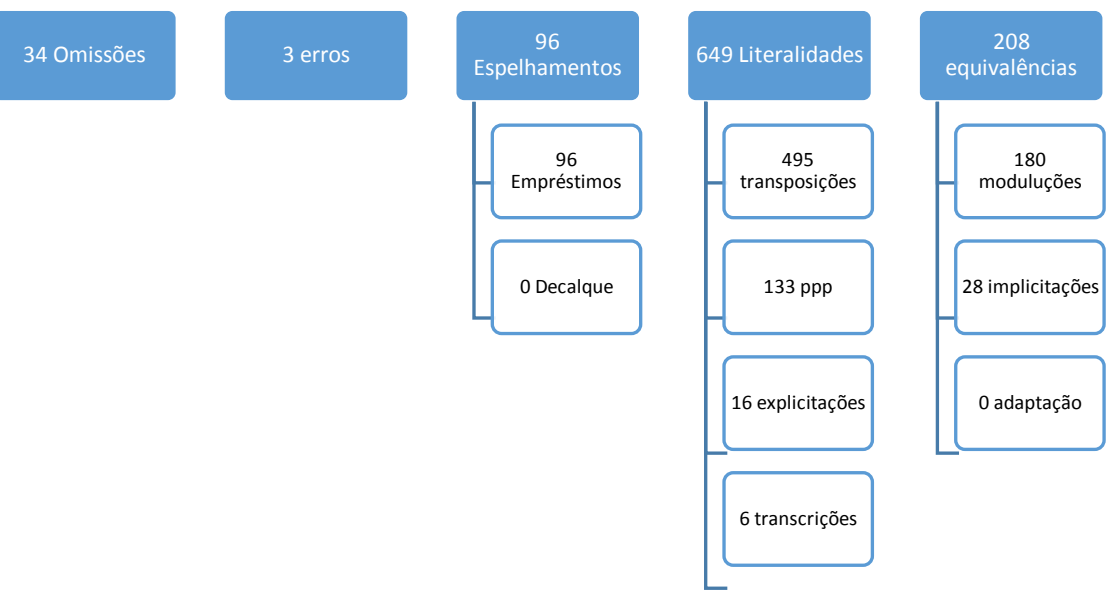

Figura 3: Modalidades de tradução no corpus

Após a busca de todas as etiquetas encontradas no corpus, obteve-se o seguinte resultado: 34 omissões, 96 ocorrências de espelhamento, 649 ocorrências de literalidade, 208 ocorrências de equivalência e 3 erros (Figura 3). Não houve no corpus nenhuma ocorrência de tradução intersemiótica, mas isso se justifica pelo próprio caráter do gênero estudado, a legenda, pois ela já se caracteriza como tradução intersemiótica, uma vez que é tradução de gênero oral para o escrito.

Dentro da etiqueta literalidade a transposição foi a modalidade mais frequente, com 495 ocorrências. Isso aconteceu devido às diferenças entre as línguas inglesa e portuguesa, já que muitas vezes a ordem do adjetivo é outra. Quando essas diferenças inexistiram de uma língua para outra, foi possível encontrar o processo de tradução palavra por palavra, tendo sido a segunda modalidade mais frequente dentro da etiqueta literalidade, com 133 ocorrências. Isso permite concluir que em grande parte do seriado não foi necessário realizar redução textual.

Ainda dentro da etiqueta literalidade temos a ocorrência da modalidade transcrição, que apareceu no corpus apenas seis vezes, e em todos os casos foi usada para a tradução de numerais que apareceram no texto fonte 
e foram repetidos no texto alvo. Isso é uma prática muito utilizada na legendagem como forma de reduzir o texto escrito. Algumas vezes, porém, a legenda em português optou por escrever o numeral por extenso. Nesse caso, não configura transcrição, mas transposição, e foram classificados como tal.

A explicitação, que ainda faz parte da etiqueta literalidade, foi uma modalidade de tradução que causou estranhamento ao aparecer no corpus. Se for levado em conta o caráter sintético da legendagem, a explicitação não deveria ocorrer. Porém, foram encontrados 16 casos no corpus. A maioria das explicitações, no entanto, ocorre justamente em busca da condensação própria da legendagem. Um exemplo:

\begin{tabular}{|l|l|}
\hline Inglês & Can your little birds find their way into Meereen? \\
\hline Português & Seus informantes conseguiriam entrar em Meereen? \\
\hline
\end{tabular}

Quadro 3: Explicitação

A explicitação se fez necessária por dois motivos: primeiro porque os termos "pequenos pássaros" ou "passarinhos" tornariam a legenda muito longa; segundo porque little birds só faz sentido nesse contexto para quem assiste ao seriado regularmente.

A etiqueta de equivalência, que ocorreu 208 vezes no corpus de estudo, como já foi dito, se divide nas modalidades modulação, implicitação e adaptação. Modulação foi a modalidade de equivalência que mais ocorreu, com 180 aparições. Aubert (2006) afirma que ela ocorre sempre que o segmento de texto mantém o sentido, mas a estrutura é alterada. Nem todas as vezes em que houve modulação deu-se uma redução textual, porém essa modalidade muitas vezes foi usada para esse fim. Como no exemplo abaixo:

\begin{tabular}{|l|c|}
\hline Inglês & You belong to me now, he said. \\
\hline Português & Ele disse: Agora você é minha. \\
\hline
\end{tabular}

Quadro 4: Modulação 
Se o legendista tivesse traduzido de forma literal - "você pertence a mim agora, ele disse" -, o tempo disponível não seria suficiente para o espectador ler a legenda.

A modalidade implicitação contabilizou 28 entradas. Sempre que ocorre no corpus, a implicitação retira alguma informação redundante, proporcionando a redução necessária para a legenda ser lida com conforto. $\mathrm{Na}$ implicitação não ocorreu perda de conteúdo para o espectador, pois além de contar com a imagem, nenhuma informação relevante foi suprimida.

A última modalidade da equivalência é a adaptação, que não ocorreu nenhuma vez no corpus. Isso pode ser explicado devido ao gênero do seriado: fantasia. Aubert (2006) explica que a adaptação se dá no confronto entre duas realidades extralinguísticas. No entanto, se o texto não confronta realidades extralinguísticas, mas trata de uma realidade que deve ser tratada como verossímil ${ }^{3}$ pelo espectador para que todo o texto possa fazer sentido, não há que se falar em adaptação.

No que diz respeito à etiqueta espelhamento, que é composta pelas modalidades empréstimo e decalque, apenas as do tipo empréstimo foram encontradas no corpus, com 96 ocorrências. Em todos os casos os empréstimos eram de nomes próprios, seja de lugar ou personagem. Alguns nomes, porém, o legendista optou por traduzir. Nesse caso houve a modalidade de transposição ou tradução palavra por palavra, mas não o empréstimo. Black Water Bay, por exemplo, foi traduzida por baía Água Negra.

No corpus analisado foram encontradas 34 ocorrências da modalidade omissão. Ela ocorre quando não se pode recuperar no texto meta alguma informação contida no texto de partida (Aubert, 2006). As omissões são esperadas na legendagem por seu caráter reduzido. Observe-se o exemplo:

\begin{tabular}{|l|l|}
\hline Inglês & You have a lot of poison in your store. \\
\hline Português & Você possui muitos venenos. \\
\hline
\end{tabular}

Quadro 5: Omissão

\footnotetext{
${ }^{3} \mathrm{O}$ verossímil da narrativa concentra-se tanto nos princípios gerais (princípios de causalidade e de nãocontradição), quanto nas convenções de gênero: o mundo de referência é o mundo possível, definido pelo conjunto dos postulados narrativos próprio ao gênero particular (Aumont \& Marie, 2003).
} 
A legenda em questão possui apenas 1 segundo e 26 milissegundos de tempo disponível, no qual seria possível inserir em média 28 caracteres. Omitindo o segmento "em sua loja", o legendista obteve um tempo razoável de leitura, 27 caracteres para o tempo disponível. A omissão, porém, não dificultou a compreensão da mensagem, cujo sentido poderia ser recuperado pelo contexto, como no exemplo acima em que se sabe que o personagem, equivalente a um boticário, possui uma loja.

Por fim, foram encontradas três ocorrências de erro no corpus. Os erros na legendagem de fãs podem ocorrer por, pelo menos, dois motivos: a própria falta de conhecimento na língua e a rapidez com que essas legendas são confeccionadas. Apesar de passarem por um processo de revisão, sua natureza implica uma rapidez de publicação que pode acarretar erros. Ainda assim, é importante observar que, por se tratar de uma legendagem não profissional, o número de erros foi bastante baixo.

\begin{tabular}{|l|l|}
\hline Inglês & while you tore at her clothes and beat her. \\
\hline Português & depois de humilhá-la e espancá-la. \\
\hline \multicolumn{2}{|c|}{ Quadro 6: Erro }
\end{tabular}

A conjunção while não equivale ao advérbio "depois", alterando, assim, a ordem dos acontecimentos. Além disso, houve uma alteração errônea do sujeito. Em inglês, tem-se nas legendas anteriores: Oh, why don't you tell them what Joffrey was doing? / Pointing a loaded crossbow at Sansa Stark / while you tore at her clothes and beat her. Em inglês, é possível perceber que as ações de rasgar as roupas e bater não são feitas por Joffrey e sim pelo interlocutor do falante em questão. Já em português, a legenda dá a entender que o personagem Joffrey é o agente de todas as ações: "Por que não diz o que Joffrey estava fazendo? / Apontava a besta para Sansa / depois de humilhá-la e espancá-la." Esse erro poderia causar dificuldade de compreensão por parte do espectador. 


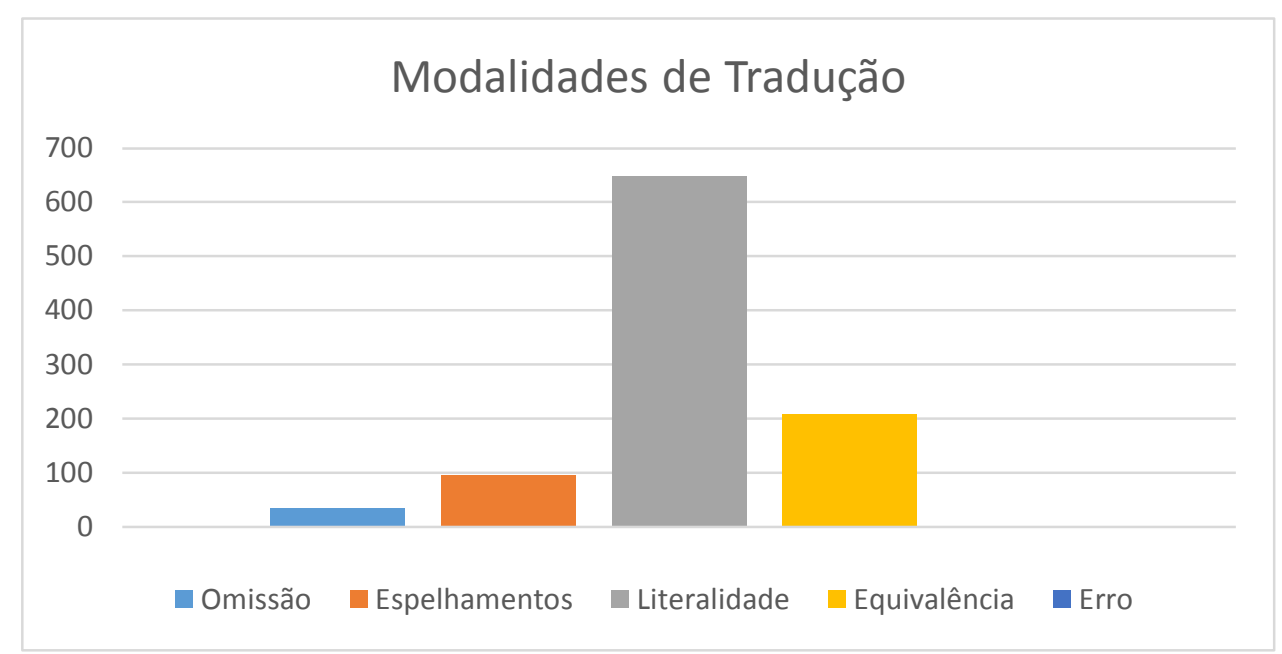

Gráfico 1: Comparativo em números absolutos por modalidade.

Nesta seção foram contabilizadas as modalidades de tradução mais frequentemente utilizadas por legendistas amadores, além de destacado o emprego de algumas dessas modalidades como forma de redução textual própria do gênero legendagem. Foram encontradas em ordem de maior para menor frequência: transposição, modulação, palavra por palavra, empréstimo, omissão, implicitação, explicitação, transcrição e erro. As modalidades decalque, adaptação e tradução intersemiótica não foram encontradas no corpus analisado. Dessa forma, é possível concluir que a literalidade foi a modalidade mais presente no corpus estudado.

Além disso, foi possível constatar que as modalidades modulação, omissão, implicitação e transcrição foram empregadas como estratégias de redução textual, característica comum no gênero de legendagem por suas restrições de tempo e espaço.

\section{Considerações finais}

Este trabalho se propôs a quantificar as modalidades de tradução mais utilizadas por legendistas amadores, além de observar se o uso dessas modalidades estava atrelado à redução textual própria do gênero legendagem. Para responder essas questões foi utilizada a Linguística de Corpus, por meio do software WordSmith Tools. Primeiramente, as legendas em português e em 
inglês de um episódio do seriado a ser analisado foram alinhadas com a ferramenta Viewer \& Aligner. Esse procedimento possibilitou a identificação das modalidades. Paralelamente a esse processo, ocorreu a etiquetagem da legenda em português com as modalidades encontradas. Isso facilitou a contabilização das etiquetas, além da possibilidade de vê-las em contexto.

Apesar de pequeno, o corpus de estudo permitiu perceber o predomínio do uso da literalidade e da equivalência. A primeira, por meio da transposição e da tradução palavra por palavra, e a segunda, a partir da modulação e da implicitação.

A metodologia também provou que o uso de algumas modalidades na legendagem muitas vezes está atrelado à redução textual característica desse tipo de tradução audiovisual. Além de as modalidades de implicitação, modulação, transcrição e omissão cumprirem esse papel, foi possível perceber que a modalidade explicitação também foi utilizada como forma de reduzir o texto da legenda para que essa pudesse ser lida com conforto pelo espectador. Quando a redução não se fazia necessária, os legendistas amadores optaram pela transposição e/ou tradução palavra por palavra, sendo que a transposição foi a modalidade mais recorrente em todo o corpus de estudo. A presença frequente da literalidade mostrou que, muitas vezes, a redução textual não foi necessária e, portanto, não ocorreu.

Outro dado importante extraído do corpus foi a baixa frequência de erros. Apesar de ser uma tradução confeccionada por amadores, em um total de 645 legendas em português apenas 3 erros foram encontrados. Um valor que pode ser considerado baixo se for levado em conta a rapidez com que essas traduções são lançadas na internet.

É preciso ressaltar que a metodologia baseada em corpus foi bastante eficaz para este estudo porque proporcionou o alinhamento dos textos, possibilitando perceber com mais clareza cada modalidade utilizada. Além disso, facilitou a contabilização das modalidades e sua observação em contexto.

Não se pretende encerrar o assunto com este trabalho, mas, ao contrário, incentivar mais pesquisas na área para aprimorar a análise de legendas feitas por fãs e, assim, desenvolver uma tradução de qualidade que atenda satisfatoriamente ao público, proporcionando acessibilidade cultural. 
Sugerem-se, portanto, futuras pesquisas com corpora de estudo maiores, além de pesquisas de recepção com o público alvo.

\section{Referências}

ARAÚJO, V. L. S. Closed Subtitling in Brazil. ORERO, P. (Org.). Topics in Audiovisual Translation. Amsterdã: John Benjamins Publishing Company, 2004. v. 1, p. 199-212.

AUBERT, F. H. Modalidades de tradução: teoria e resultados. São Paulo: TradTerm, 1998. v. 5.1, p. 99-128.

. Em busca das refrações na literatura brasileira traduzida: revendo a ferramenta de análise. São Paulo: Literatura e sociedade, 2006. v. 9, p. 60-69.

AUMONT, J; MARIE, M. Dicionário teórico e crítico de cinema. Tradução Eloísa Araújo Ribeiro. 2. ed. Campinas: Papirus, 2003.

CINTAS, J; REMAEL, A. Audiovisual translation: subtitling. Manchester: St. Jerome Publishing, 2007.

CHAUME, F. Cine y traducción. Madri: Cátedra, 2004.

DE LINDE, Z.; KAY, N. The semiotics of subtitling. Manchester: St. Jerome Publishing, 1999.

D'YDEWALLE, G. Reading a message when the same message is available auditorily in another language: the case of subtitling. In LÉVY-SCHOEN, A. (Org.). Eye movements: from physiology to cognition. Amsterdam \& New York: Elsevier Science Publishers, 1987. p. 313-321.

EQUIPE INSUBS. Como é o mundo das legendas? Disponível em: http://insubs.tumblr.com/. Acesso em 10 de maio de 2014.

GOTTLIEB, H. Subtitling. In BAKER, M. (Org.). Routledge encyclopedia of translation studies. Manchester: St. Jerome, 1998. p. 244-248.

IVARSON, J.; CARROL, M. Subtitling. Simrishamn, Suécia: GraphoTryck AB, 1998.

The laws of gods and men. Game of thrones. Direção de Alik Sakharov. HBO, 2014 (52 min.).

Resumo: A legendagem de fãs no Brasil surgiu com a grande popularidade de séries e filmes estrangeiros. Muitos fãs que sabiam o idioma do programa resolveram juntar-se em grupos e produzirem eles mesmos as traduções. Essas legendas estão bastante difundidas na internet, e existem sites especializados para encontrá-las. A presente pesquisa procura descobrir quais são as modalidades de tradução mais utilizadas pelos legendistas amadores e se essas estão, de alguma forma, associadas às estratégias de redução textual da legendagem, que leva em conta o limitado tempo disponível em tela para leitura e a linguagem multimodal de um produto audiovisual. 
Palavras-chave: legendagem de fãs; tradução audiovisual; modalidades de tradução

Abstract: Fan subtitling in Brazil emerged with the great popularity of foreign films and TV shows. Hence, many fans who knew the language of the program decided to join together in groups that produced the translations. This research aimed to discover which modalities are used the most by amateur subtitlers and if they are, somehow, in accordance with the strategies of textual reducing inherent to subtitling, in which one must take into account the limited time available on the screen on an audiovisual product. Keywords: fan subtitling; audiovisual translation; translation modalities. 